\title{
Oronasal mask versus helmet in acute hypercapnic respiratory failure
}

\author{
Lara Pisani ${ }^{1}$, Chiara Mega ${ }^{1}$, Rosanna Vaschetto ${ }^{2}$, Andrea Bellone $^{3}$, \\ Raffaele Scala ${ }^{4}$, Roberto Cosentini ${ }^{5}$, Muriel Musti ${ }^{6}$, Manuela Del Forno ${ }^{1}$, \\ Mario Grassi ${ }^{7}$, Luca Fasano ${ }^{8}$, Paolo Navalesi ${ }^{9-11}$ and Stefano Nava ${ }^{1}$ \\ Affiliations: ${ }^{1}$ Alma Mater University, Dept of Clinical, Integrated and Experimental Medicine (DIMES), \\ Respiratory and Critical Care Unit, S. Orsola-Malpighi Hospital, Bologna, Italy. 2"Maggiore Della Carità" \\ Hospital, Dept of Anesthesia and Intensive Care, Novara, Italy. ${ }^{3}$ Sant'Anna Hospital, ED, Como, Italy. \\ ${ }^{4}$ U.O. Pneumologia, Ospedale S. Donato, ASL 8, Arezzo, Italy. 'IRCCS Fondazione Ca' Granda, Ospedale \\ Maggiore Policlinico, Emergency Medicine Dept, Milan, Italy. ${ }^{6}$ Public Health-Care, Dept of Epidemiology, \\ Bologna, Italy. ${ }^{7}$ Dept of Brain and Behavioural Sciences, Medical and Genomic Statistics Unit, Università degli \\ Studi di Pavia, Pavia, Italy. ${ }^{8} \mathrm{~S}$. Orsola-Malpighi Hospital, Respiratory and Critical Care Unit, Bologna, Italy. \\ ${ }^{9}$ Dept of Translational Medicine, Eastern Piedmont University “A. Avogadro", Novara, Italy. ${ }^{10}$ Anesthesia and \\ Intensive Care, Sant'Andrea Hospital, ASL, Vercelli, Italy. ${ }^{11}$ CRRF Mons. L. Novarese, Moncrivello, Italy.
}

Correspondence: Stefano Nava, Respiratory and Critical Care Unit, S. Orsola-Malpighi Hospital, Alma Mater University, DIMES, Via Massarenti n. 9, 40137 Bologna, Italy. E-mail: stefanavalagmail.com

ABSTRACT The choice of the interface for noninvasive ventilation (NIV) is a key factor in NIV success. We hypothesised that a new helmet specifically design to improve performance in hypercapnic patients would be clinically equivalent to a standard oronasal mask.

In a multicentre, short-term, physiological, randomised trial in chronic obstructive pulmonary disease patients facing an acute hypercapnic respiratory failure episode, we compared the changes in arterial blood gases (ABGs) and tolerance score obtained using the helmet or mask, and, as secondary end-points, dyspnoea, vital signs, early NIV discontinuation and rate of intubation. 80 patients were randomly assigned to receive NIV either with the helmet $(n=39)$ or mask $(n=41)$, using an intensive care unit ventilator.

Compared with baseline, in the first $6 \mathrm{~h}$, NIV improved ABGs, dyspnoea and respiratory rate $(\mathrm{p}<0.05)$ in both groups. Changes in ABGs and discomfort were similar with the two groups, while dyspnoea decreased more $(p<0.005)$ using the mask. The rate of intubation and the need for interface change during the whole period of NIV were very low and not different between groups.

The new helmet may be a valid alternative to a mask in improving ABGs and achieving a good tolerance during an episode of acute hypercapnic respiratory failure.

@ERSpublications

In COPD patients undergoing NIV, an oronasal mask and a helmet equally improved ABGs and tolerance score http://ow.ly/DMVIg 


\section{Introduction}

Noninvasive mechanical ventilation (NIV) has been increasingly used to avoid or serve as an alternative to intubation. Compared with medical therapy, and in some instances with invasive mechanical ventilation, it improves survival and reduces complications in selected patients with acute respiratory failure [1-3].

The rate of NIV failure depends on the underlying cause of acute respiratory failure, the severity of the patients' disease and, last but not least, poor tolerance and discomfort. The choice of the interface represents therefore a key factor for NIV success $[4,5]$. In real life, the oronasal mask is considered the first choice of interface [6] because it minimises the problem of air leaks and allows breathing through both nose and mouth. Randomised controlled trials (RCTs) [7, 8] showed that oronasal and full-face masks are equally tolerated and effective in improving gas exchange, but early discontinuation because of intolerance may be quite high with both interfaces [7]. It has therefore been suggested that if NIV has to be prolonged beyond $24 \mathrm{~h}$, it would appear reasonable to switch to different interfaces to improve patient comfort and avert skin lesions [9].

Several studies have shown that the helmet is a valuable interface in hypoxaemic patients [10-14] with the advantage of avoiding skin lesions regardless of face morphology while improving patient comfort. Despite the promising results of a case-control study showing better tolerance with the helmet versus the oronasal mask [15], its use in acute hypercapnic respiratory failure (AHRF) is still more controversial, as the same study demonstrated a lesser efficacy in reducing arterial carbon dioxide tension $\left(\mathrm{PaCO}_{2}\right)$ in the helmet group. Indeed, concerns were raised about the poor synchrony between the patient and the ventilator because of its soft, compliant wall, and the elevated internal compressible volume and dead space [16]. A recent bench study, however, showed that the effective dead space is not only related to the internal gas volume [17]. Moreover, a new helmet specifically designed to improve performance in hypercapnic patients [18], as well as the use of specific ventilator settings with high inspiratory and expiratory pressures and the fastest pressurisation rate, can improve patient-ventilator interaction [19]. In this pilot study, we wanted to test the hypothesis that the use of the new helmet combined with the use of "specific" settings would result in similar changes in arterial blood gases (ABGs), particularly carbon dioxide clearance, versus the oronasal mask, at the same time, allowing similar comfort for the patient.

Secondary outcomes were dyspnoea, vital signs, and the rate of NIV discontinuation and intubation using the two different interfaces.

\section{Materials and methods}

Data were collected from September 2012 to July 2014. Patients affected by AHRF admitted to one of two emergency departments (in Como and Milan, Italy) or three intensive care units (Arezzo, Bologna and Vercelli, Italy) were enrolled. These latter units are in a pulmonary division with a dedicated intensive care unit (ICU) and respiratory ward. The protocol was approved by the institutional review boards at each centre and written informed consent was obtained from each patient. This study is registered with www. clinicaltrials.gov with identifier number NCT01645358.

Inclusion criteria were the presence of chronic obstructive pulmonary disease (COPD) and AHRF $\left(\mathrm{pH}<7.35, \mathrm{PaCO}_{2}>45 \mathrm{mmHg}\right.$ and arterial oxygen tension/inspiratory oxygen fraction ratio <250 while breathing room air or with oxygen supplementation via a Venturi mask). Due to the fact that the helmet could be only used with ICU ventilators, we enrolled only consecutive patients admitted to the ICU and not those admitted to respiratory wards within the same time frame.

Exclusion criteria were: 1) unstable clinical condition (need for vasopressors for $>24 \mathrm{~h}$, acute coronary syndrome or life-threatening arrhythmias); 2) refusal of treatment; 3) a weak cough reflex; 4) agitation or non-cooperation; 5) failure of more than two organs; 6) cardiac arrest; 7) respiratory arrest requiring tracheal intubation; 8) recent trauma or burns of the neck and face; and 9) pregnancy.

Patients' baseline characteristics are shown in table 1. Dyspnoea score was recorded using the Borg scale [20]; secretion amount was quantified on a scale where 1 is normal, 2 minimal and 3 abundant [21]; and neurological status with the Kelly and Matthay [22] scale, which is specifically designed for respiratory patients. The number of comorbidities was evaluated using Charlson Comorbidity Index scoring system [23].

\section{Ventilator and interfaces}

All patients received NIV via a standard ICU ventilator with double-tube circuit in pressure-support mode. They were randomly assigned to receive NIV with the helmet or mask.

\section{Helmet group}

The new helmet (Castar-R Next; Starmed, Mirandola, Italy) is a transparent and latex-free polyvinylchloride hood joined to a soft collar by a rigid plastic ring, with an inflatable cushion placed 
TABLE 1 Baseline characteristics of the patients

\begin{tabular}{|c|c|c|c|}
\hline & Helmet & Mask & p-value \\
\hline Subjects $\mathrm{n}$ & 39 & 41 & \\
\hline Age years & $78.36 \pm 10.58$ & $78.48 \pm 7.75$ & 0.3980 \\
\hline Kelly score & $2.28 \pm 1.21$ & $2.19 \pm 1.23$ & 0.7143 \\
\hline SAPS II & $35.41 \pm 10.36$ & $35.68 \pm 10.51$ & 0.9494 \\
\hline Dyspnoea score & $7.68 \pm 2.20$ & $7.06 \pm 2.75$ & 0.5200 \\
\hline Charlson index & $3.49 \pm 1.60$ & $3.49 \pm 1.88$ & 0.7167 \\
\hline Secretions & $1.78 \pm 0.95$ & $2.10 \pm 1.04$ & 0.1678 \\
\hline Systolic blood pressure $\mathrm{mmHg}$ & $139.15 \pm 31.03$ & $140.8 \pm 31.85$ & 0.7419 \\
\hline Diastolic blood pressure $\mathrm{mmHg}$ & $73.23 \pm 17.47$ & $73.38 \pm 21.26$ & 0.9293 \\
\hline Heart rate beats per min & $98.08 \pm 17.58$ & $98.02 \pm 20.27$ & 0.8163 \\
\hline Respiratory rate breaths per min & $30.82 \pm 8.10$ & $32.88 \pm 8.75$ & 0.2796 \\
\hline Body temperature ${ }^{\circ} \mathrm{C}$ & $36.40 \pm 0.42$ & $36.70 \pm 0.85$ & 0.4687 \\
\hline Arterial pH & $7.27 \pm 0.05$ & $7.26 \pm 0.06$ & 0.8250 \\
\hline $\mathrm{PaO}_{2} \mathrm{mmHg}$ & $70.84 \pm 31.05$ & $68.95 \pm 39.97$ & 0.2093 \\
\hline $\mathrm{PaCO}_{2} \mathrm{mmHg}$ & $72.58 \pm 14.87$ & $74.45 \pm 15.25$ & 0.5366 \\
\hline $\mathrm{HCO}_{3}^{-} \mathrm{mmol} \cdot \mathrm{L}^{-1}$ & $30.68 \pm 6.97$ & $31.32 \pm 7.24$ & 0.6273 \\
\hline $\mathrm{PaO}_{2} / \mathrm{FlO}_{2}$ & $193.33 \pm 50.74$ & $194.05 \pm 67.89$ & 0.7167 \\
\hline
\end{tabular}

Data are presented as mean \pm SD unless otherwise stated. SAPS II: Simplified Acute Physiology Score; $P_{\mathrm{aO}_{2}}$ : arterial oxygen tension; $\mathrm{PaCO}_{2}$ : arterial carbon dioxde tension; $\mathrm{FlO}_{2}$ : inspiratory oxygen fraction.

underneath the rigid ring. It has less internal volume of the latter than a continuous positive airway pressure helmet, consequent to the reduced dimensions of the hood and the presence of an inflatable cushion placed above the collar to reduce the dead space (fig. 1). The annular openable ring is the major characteristic of the new helmet because it secures the interface without armpit belts. Compared with the standard helmet, it improves the rate of pressurisation, triggering performance [24], patient-ventilator synchrony by avoiding or at least reducing, to a large extent, the downward displacement of the soft collar during ventilator insufflation [18]. Every patient in the helmet group was evaluated by measuring neck circumference to determine the best size to attain a good seal and avoid air leaks (small, medium and large sizes). It is important to note that to eventually remove the helmet, the patients should be able to call the nurse, as it is problematic to do it alone. This helmet is widely available in some European countries and has CE approval.

The ventilator settings for the helmet needed higher pressures according to published data [19], and we set a positive end-expiratory pressure (PEEP) of $>5 \mathrm{cmH}_{2} \mathrm{O}$ and an inspiratory pressure support of $\geqslant 16 \mathrm{cmH}_{2} \mathrm{O}$, keeping a flow rate $>30 \mathrm{~L} \cdot \mathrm{min}^{-1}$ inside the helmet; other pressure increments were made to keep respiratory rate $<20$ breaths per min and minimising, by visual inspection, the occurrence of accessory
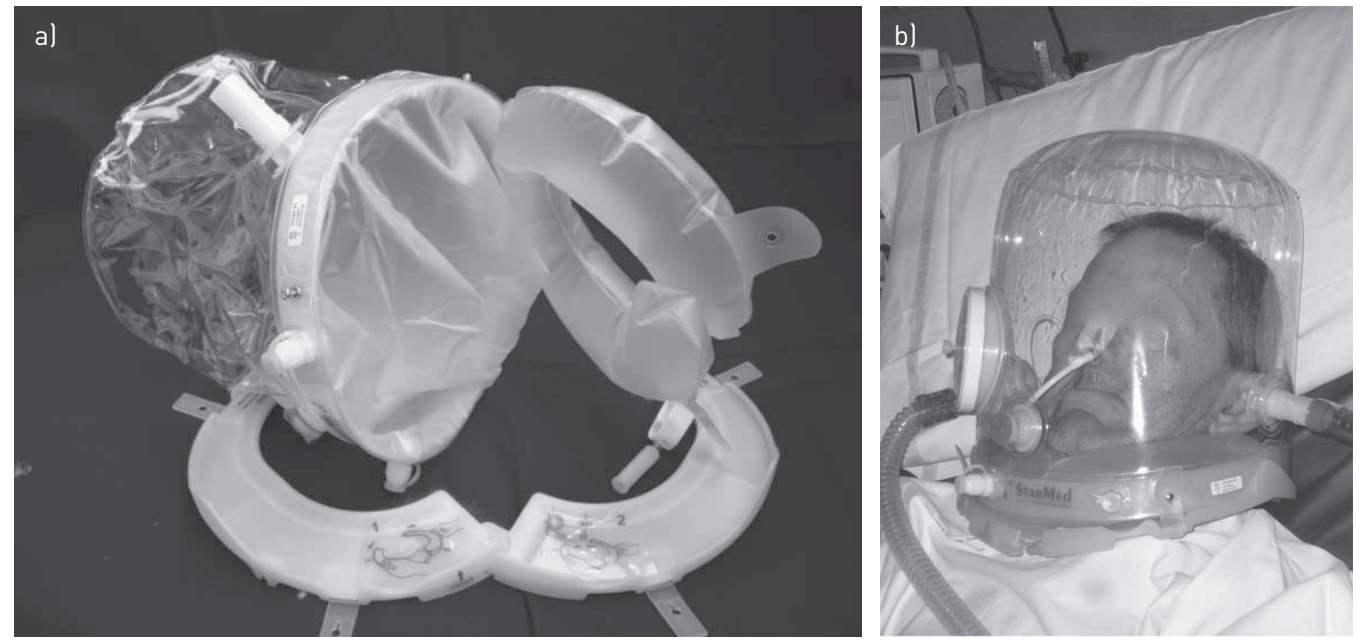

FIGURE 1 The new helmet (Castar-R Next; Starmed, Mirandola, Italy). a) Rigid plastic ring can be seen in the open position. b) The helmet in use on a patient. 
muscle recruitment. The fastest rate of pressurisation and a cycling-off flow threshold from $25 \%$ to $50 \%$ of the peak inspiratory flow were also set. Further changes were eventually made according to ABGs.

\section{Mask group}

The oronasal mask assigned to each patient was chosen according to anthropometric characteristics, minimisation of air leaks and patient tolerance, from the following interfaces available in all the units: FreeMotion RT041 Non Vented Full Face Mask (Fisher and Paykel, Auckland, New Zealand); Ultra Mirage FFM-NV(ResMed, Vimercate, Italy); and PerforMax Face Mask (Philips Respironics, Monza, Italy).

The ventilator settings were decided according to the usual practice: maximal tolerated inspiratory pressure to obtain a tidal volume of $6-8 \mathrm{~mL} \cdot \mathrm{kg}^{-1}$ of body weight and PEEP between 3 and $5 \mathrm{cmH}_{2} \mathrm{O}$.

\section{Randomisation}

Patients were randomly assigned to one of the two treatment groups using opaque, sealed, numbered envelopes. We used a computer-generated randomisation sequence, which was generated by an independent biostatistitian who was not otherwise involved in the trial. The envelopes were kept in the head nurses' offices in every institution's critical care unit. The nurses who opened the envelopes were those on shift that day or night and were totally independent from the enrolment process. They communicated the random treatment allocation to the attending physician who assigned the patients to the study group. If the patients required discontinuation of NIV because of interface intolerance, they could eventually be switched to the other interface.

\section{End-points and definitions}

Our primary end-points were to assess the following. 1) ABGs after 1 and $6 \mathrm{~h}$ of NIV application. 2) The differences in discomfort (using a numerical analogue scale from 0 to 10). To this end, the nurse asked to the patient at the predetermined times: "Mark on this paper your discomfort wearing this interface, where 10 is the worst you can imagine and 0, no discomfort at all" [25]. 3) The number of patients needing to change the interface throughout the whole NIV period and the reason for that.

The secondary end-points were as follows. 1) Changes in dyspnoea score during NIV using the Borg scale. At the time of recording, the patient was asked by a nurse not involved in the study design: "How do you feel your breathing is now?" 2) Vital signs (respiratory rate, blood pressure, heart rate and body temperature). 3) Discontinuation of NIV, defined as the inability of the patient to continue NIV while there was still and indication for ventilatory support. 4) NIV failure and endotracheal intubation.

Patients were considered as being "at risk of NIV failure" when after two continuous hours of NIV, at least one of the following was observed: arterial $\mathrm{pH} \leqslant 7.30$ with $\mathrm{PaCO}_{2}>20 \%$ of the baseline value, respiratory rate $\geqslant 30$ breaths per min and use of accessory muscles or paradoxical abdominal movements [26]. The decision to intubate was taken by the attending clinicians according to pre-defined criteria. The major criteria included respiratory arrest, respiratory pauses with loss of consciousness, psychomotor agitation making nursing care impossible and requiring sedation, heart rate $<50$ beats per min with loss of alertness, and haemodynamic instability with systolic arterial blood pressure $<70 \mathrm{mmHg}$; development of conditions requiring intubation either to protect the airways or to manage copious tracheal secretions; and inability of the patient to tolerate the oronasal mask or helmet [27].

\section{Statistical analysis}

Data are presented as mean \pm SD and range. Statistical analysis was performed using Stata Intercooled 12.0 statistical analysis software (StataCorp, College Station, TX, USA).

In this noninferiority study, the scheduled sample size of $30 \times 2=60$ patients, estimated using the $\mathrm{R}$ package Trialsize [28], would allow us to test noninferiority of the mask compared with the helmet, with a statistical power of $80 \%$ at the level of $\mathrm{p}<0.05$ (one sided), assuming a common standard deviation of $15 \mathrm{mmHg}$, the true difference in mean between treatment groups is zero and the noninferiority margin to be $10 \mathrm{mmHg}$. This calculation was based on expected baseline $\mathrm{PaCO}_{2}$ values of $80 \mathrm{mmHg}$, according to the average admission value in our unit in the last 3 years [29]. Hypothesising 30\% drop-out rate, it was therefore necessary to include 80 patients [15].

The Kruskal-Wallis test was used to examine between-group differences at baseline, and 1 and $6 \mathrm{~h}$ after randomisation. Friedman's ANOVA test was used to analyse within-group differences over time. $\mathrm{p}<0.05$ was considered to be statistically significant. 


\section{Results}

80 patients were enrolled in the study and randomly assigned to the helmet group $(n=39)$ or full-face mask group $(n=41)$. Figure 2 is a flowchart of patients according to interface assignment.

As illustrated in figure 3, NIV significantly improved ABGs after 1 and $6 \mathrm{~h}$ of ventilation in both groups. No statistical differences were reported between the groups.

As shown in figure 4, interface discomfort score was similar between groups, but with a trend toward worsening comfort at $6 \mathrm{~h}$ in the helmet group.

Table 2 shows the number of patients requiring a change of interface throughout the whole period of mechanical ventilation and the reasons for this. These events were homogeneously distributed among the two groups. None of the patients required stopping NIV because of poor tolerance. The same table illustrates also the side-effects in the two groups not requiring a change in the interface or discontinuation of NIV.

Dyspnoea and respiratory rate decreased significantly from baseline during the first $6 \mathrm{~h}$ of NIV but the changes in the former parameter were significantly greater in the oronasal group (table 3 ). Final settings with the helmet were an inspiratory support of $19.62 \pm 5.67 \mathrm{cmH}_{2} \mathrm{O}$ and PEEP of $7.72 \pm 1.85 \mathrm{cmH}_{2} \mathrm{O}$. The corresponding values with the mask were $16.37 \pm 4.19 \mathrm{cmH}_{2} \mathrm{O}$ and $4.26 \pm 1.92 \mathrm{cmH}_{2} \mathrm{O}$.

In the mask group, two patients were intubated after $24 \mathrm{~h}$ for severe acidosis.

\section{Discussion}

In this study, we have found: that the oronasal mask and helmet are equivalent in improving ABGs, particularly carbon dixoide clearance, from baseline conditions; that they are perceived as similarly comfortable by patients with AHRF receiving NIV; and that very few patients, equally distributed in the two groups, required a switch from one interface to the other. Moreover, changes in vital signs, with the exclusion of dyspnea score, were also similar in the two groups. The novelties of the present investigation are that this is the first randomised trial comparing these two interfaces, which are widely used in the clinical practice [6], and that we have applied a new model of helmet $[18,24]$ and specific ventilatory settings [19] that are able to minimise the well-known drawbacks of this kind of interface.

The choice of interface during NIV represents one of the main determinants of its success in an acute setting; therefore, the availability of different types of interfaces could allow different approaches in confronting each individual situation, optimising patient tolerance and avoiding side-effects [30]. It has been also proposed that in patients requiring several hours of mechanical ventilation, the rotation of different interfaces might avoid, or at least reduce, the risk of skin breakdown, by alternating the distribution of pressure on the skin and thus varying the point of maximal friction [9].

FIGURE 2 Study design. COPD: chronic obstructive pulmonary disease; NIV: noninvasive ventilation.

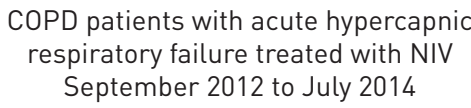

39 patients were excluded 11 meeting exclusion criteria

12 not randomised 6 refused consent 10 unable to understand or sign the consent

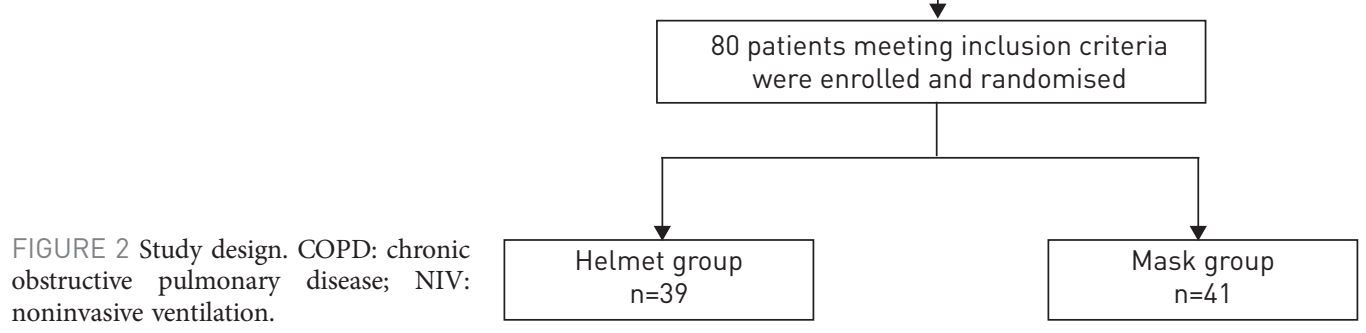



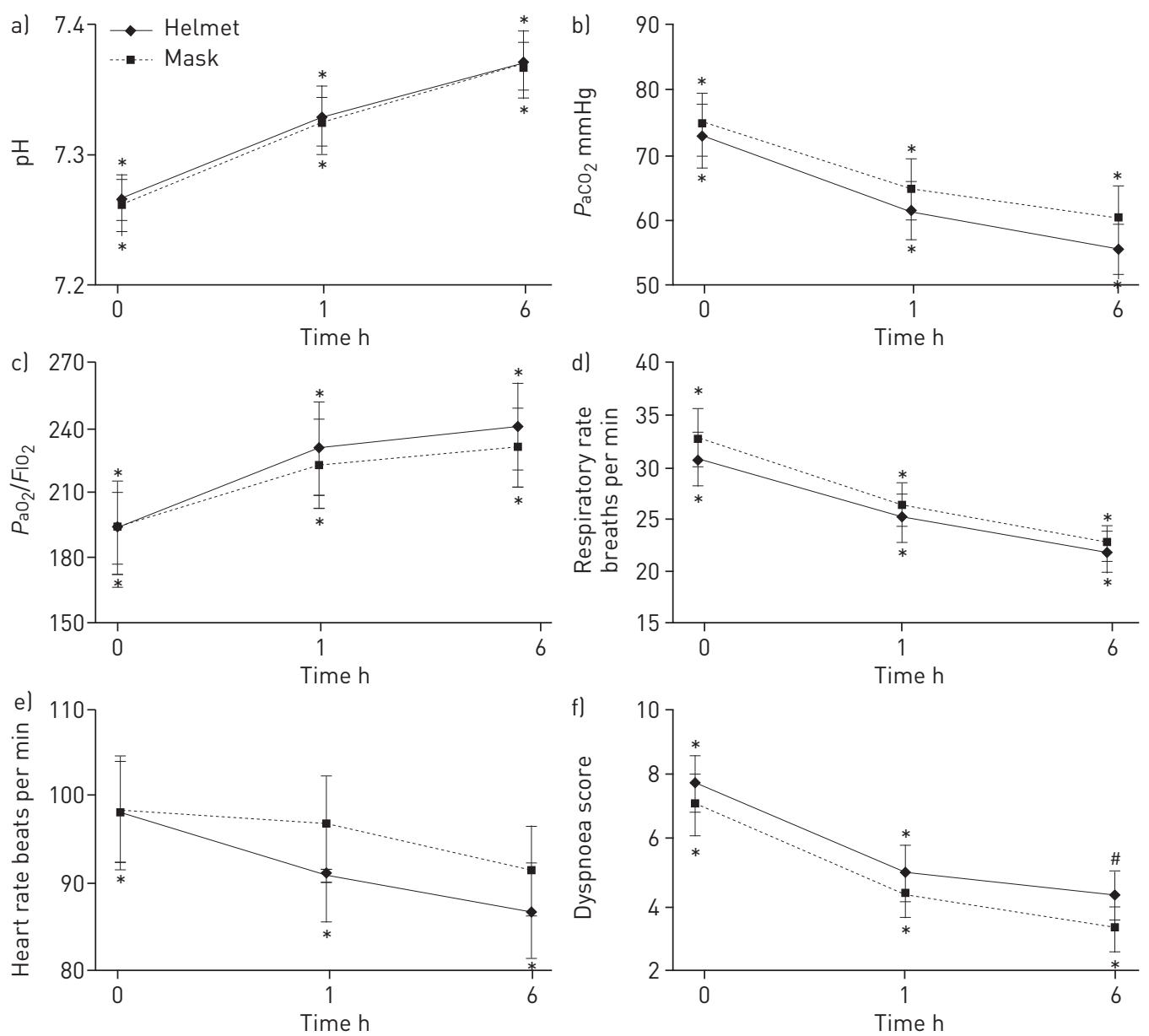

FIGURE 3 Gas exchange and vital signs modifications during the study. a) $\mathrm{pH}$; b) arterial carbon dioxide tension $\left.\left(\mathrm{PaCO}_{2}\right) ; \mathrm{c}\right)$ arterial oxygen tension $\left(\mathrm{PaO}_{2}\right)$ /inspiratory oxygen fraction ratio $\left.\left(\mathrm{FiO}_{2}\right) ; \mathrm{d}\right)$ respiratory rate; e) heart rate; $\left.\mathrm{f}\right)$ dyspnoea score. ${ }^{*}$ : $\mathrm{p}<0.05$ over time from baseline; ${ }^{*}: \mathrm{p}<0.05$ for oronasal mask versus helmet.

A web survey conducted in $\sim 300$ ICUs and respiratory wards in the European Union showed that oronasal masks were the most frequently used interfaces, followed by full-face masks, nasal masks and helmets [6]. The main reasons for choosing a particular interface were geographical area, patient comfort, the prevention of leaks or complications, and costs.

Interestingly, while RCTs have assessed, with a face-to-face comparison, the efficiency of the different kinds of masks, no study has been performed using the helmet. This kind of interface has been used mainly in patients with hypoxic respiratory failure, mostly in those patients who are immunocompromised, with a high rate of success in avoiding endotracheal intubation [10-14]. Indeed, when compared in case-control studies with the oronasal mask, the patient's tolerance (i.e. the number of hours of continuous

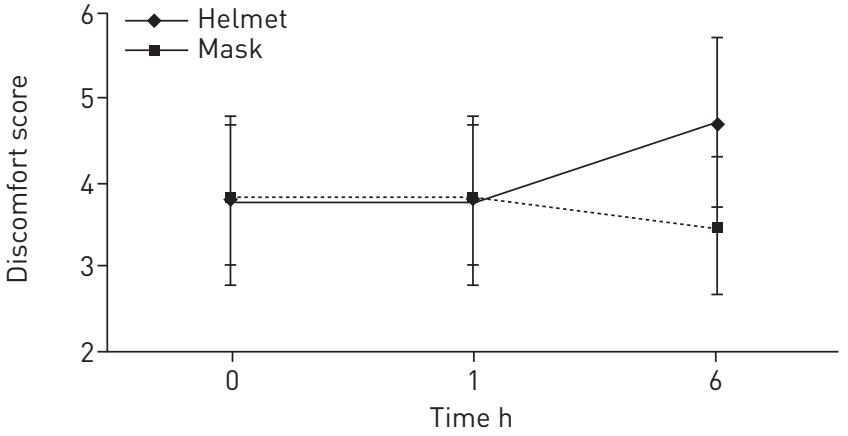

FIGURE 4 Discomfort score changes during the study. 
TABLE 2 Number of patients requiring a change of interface throughout the whole period of mechanical ventilation and the side-effects in the two groups

\begin{tabular}{lcc} 
& Helmet & Mask \\
\hline Subjects $n$ & 39 & 41 \\
Change of interface & $2(5.1)$ & $1(2.4)$ \\
Reason & Claustrophobia in $2(5.1)$ & Deterioration of ABGs in $1(2.4)$ \\
ETI & $0(0)$ & $2(4.8)$ \\
Side-effects & $4(10.2)$ & $0(0)$ \\
$\quad$ Noise & $2(5.1)$ & $1(2.4)$ \\
Claustrophobia & $2(5.1)$ & $2(4.8)$ \\
Gastric distension & $0(0)$ & $1(2.4)$ \\
Vomiting & $0(0)$ & $0(0)$ \\
Sweating & $3(7.6)$ & $5(12.1)$ \\
Tightness & & \\
\hline Data are presented as $\mathrm{n}(\%)$ unless otherwise stated. ETI: endotracheal intubation; ABG: arterial blood gas.
\end{tabular}

NIV use without interruptions) was higher and the rate of complications directly related to the administration of NIV was lower [15].

There are, however, several drawbacks that may limit the use of this interface in clinical practice, especially in those patients with hypercapnia. 10 years ago, TACCONE et al. [31] showed that the helmet predisposes to carbon dioxide rebreathing, but this interface does not behave as a simple dead space, as the carbon dioxide concentration within it depends on the subject's carbon doxide production and the fresh gas flow, rather than helmet volume. For this reason, Mojoli et al. [32] more recently discouraged the use of low levels of pressure support in this setting.

In a bench study, Fodil et al. [17] postulated that, due to specific gas flow passing through the interface, the effective dead space added by the interface is not always related to the whole gas volume included in the interface. They showed that, despite the internal volumes of the oronasal masks and the helmet were markedly different, the effective dead spaces differed only modestly. Using the helmet, the dead space was limited to half the tidal volume, whereas for different types of oronasal masks, it was close to the interface gas volume [17].

The new-generation helmet used in this study, contrary to a standard helmet secured by armpit braces at two hooks of the metallic ring, is fixed by rigid collar. For this reason, compared with the standard helmet used in the study by ANTONelli et al. [15], it is more effective in delivering NIV in pressure mode, preventing, or at least reducing, the downward displacement of the soft collar during ventilator insufflation, simultaneously reducing the deadspace.

Compared with the standard helmet, the one used in the present investigation resulted in a significantly smaller trigger delay and inspiratory efforts, so that the matching between the patients and the ventilator was markedly improved [18]. Indeed, we chose specific settings for helmet ventilation. In fact, it was shown that, in COPD patients, the pressure-support level needed to eliminate accessory muscle activity

TABLE 3 Outcome variables in patients treated

\begin{tabular}{|c|c|c|c|c|c|c|}
\hline & \multicolumn{3}{|c|}{ T1 } & \multicolumn{3}{|c|}{$\mathrm{T} 2$} \\
\hline Subjects $\mathrm{n}$ & 41 & 39 & & 41 & 39 & \\
\hline Dyspnoea score & $4.34 \pm 2.15$ & $5.0 \pm 2.28$ & 0.0988 & $3.32 \pm 2.01$ & $4.30 \pm 2.07$ & $0.0227 *$ \\
\hline Respiratory rate breaths per min & $26.42 \pm 6.51$ & $25.16 \pm 7.21$ & 0.2500 & $22.72 \pm 5.05$ & $21.89 \pm 5.88$ & 0.4409 \\
\hline Systolic blood pressure $\mathrm{mmHg}$ & $130.11 \pm 23.95$ & $128.68 \pm 25.21$ & 0.8535 & $125.06 \pm 17.74$ & $129.47 \pm 21.84$ & 0.4461 \\
\hline Diastolic blood pressure $\mathrm{mmHg}$ & $68.81 \pm 12.63$ & $70.28 \pm 14.53$ & 0.7321 & $66.0 \pm 12.10$ & $70.66 \pm 12.71$ & 0.0839 \\
\hline
\end{tabular}

Data are presented as mean \pm SD unless otherwise stated. T1: $1 \mathrm{~h}$ after randomisation; T2: $6 \mathrm{~h}$ after randomisation; PS: pressure support; PEEP: positive end-expiratory pressure. ${ }^{*}$ : $p<0.05$. 
and patient discomfort was 33\% higher with the helmet than with the oronasal mask [19]. VARGAS et al. [19] demonstrated that the use of the highest pressurisation rate and the increase of both the pressure-support level and PEEP by $\sim 50 \%$ of the values usually employed with mask ventilation was associated not only with a better unloading but also with less discomfort, while gas exchange remained unchanged.

In our study, the ventilator pressure was $\sim 30 \%$ higher with the helmet, so is not surprising that the $A B G$ changes did not differ between the two groups. However, our results did not confirm that the helmet was better tolerated than the oronasal mask in real life, as previously suggested by several studies $[11,13,15]$.

All these previous investigations used old types of mask, most of them still using inflatable soft cushion seals. In recent years, more and more sophisticated masks have been developed in an attempt to ameliorate the patient's acceptance and comfort, while the helmet itself remained basically unchanged during these years in the shape and characteristics, if not the fixation system. Indeed, the centres participating in our studies have all great expertise in the use of NIV and with long-term use of oronasal masks, so the team (i.e. physicians, nurses and respiratory therapists) may have gained sufficient training to minimise all the potential problems usually encountered when a specific interface is applied to a patient.

Both interfaces reduced dyspnoea score significantly from baseline values but the changes were greater using the oronasal mask. This is not surprising as, despite that the matching between the patients and the ventilator was markedly improved with the new helmet versus the traditional one, a considerable amount of asynchrony remains [18] and this may have influenced the perception of the patients.

The rate of NIV discontinuation was also very low in our study, especially compared with other investigations [7,9]. The aforementioned high expertise with the technique may explain this result, as great care was taken by the teams to prevent skin damage, eye irritation and facial erythema [9]. We could only assess air leakage, claustrophobia and poor fit as causes of discomfort.

This study has some limitations. First, the severity of AHRF episode was relatively mild, with a mean $\mathrm{pH}$ at enrolment of $\sim 7.26$, which, in our experience, is associated with a failure rate $<10 \%$ [33]. Further studies are needed to explore the efficiency of the two interfaces in more compromised patients. Second, we did not assess the overall nursing workload and the time required for interface placement. Usually, these measurements have the bias to be recorded by the same operator in charge of these operations, and are therefore prone to criticism, unless the time of intervention could be recorded continuously with by a camera that, by law, cannot be used in the ICUs or emergency departments in our country. However, when the nursing workload was recorded using the "subjective" method, the use of the helmet did not require more time than the use of common facial mask, even if the access to patients requires two nurses, using the helmet [34]. Vital signs like ABGs, respiratory rate and dyspnoea were assessed regularly only for the first $6 \mathrm{~h}$, as a small percentage of patients (25 (31\%) out of 80 ) was discharged from the emergency department to the medical ward while still ventilated. However, we followed up the patients for the whole NIV trial regarding the change of interface and the reason for that, and the need for intubation.

In conclusion, in this RCT performed during an episode of AHRF in COPD patients, we have shown that the new-generation helmet may be an effective interface to improve alveolar ventilation, at the same time, achieving a similar comfort rate to that of the oronasal mask. Further, larger randomised trials should verify whether this new interface could be used as the first-line treatment or be a valid alternative to the oronasal mask for a "rotating" strategy when the latter is poorly tolerated.

\section{References}

1 British Thoracic Society Standards of Care Committee. Non-invasive ventilation in acute respiratory failure. Thorax 2002; 57: 192-211.

2 Nava S, Hill N. Non-invasive ventilation in acute respiratory failure. Lancet 2009; 374: 250-259.

3 Evans TW. International Consensus Conferences in Intensive Care Medicine: Noninvasive positive pressure ventilation in acute respiratory failure. Intensive Care Med 2000; 27: 166-178.

4 Navalesi P, Fanfulla F, Frigerio P, et al. Physiologic evaluation of noninvasive mechanical ventilation delivered with three types of mask in patients with chronic respiratory failure. Crit Care Med 2000; 28: 1785-1790.

5 Costa R, Navalesi P, Spinazzola G, et al. Influence of ventilator settings on patient-ventilator synchrony during pressure support ventilation with different interfaces. Intensive Care Med 2010; 36: 1363-1370.

6 Crimi C, Noto A, Princi P, et al. A European survey of noninvasive ventilation practices. Eur Respir J 2010; 36: 362-369.

7 Ozsancak A, Sidhom SS, Liesching TN, et al. Evaluation of the total face mask for noninvasive ventilation to treat acute respiratory failure. Chest 2011; 139: 1034-1041.

8 Cuvelier A, Pujol W, Pramil S, et al. Cephalic versus oronasal mask for noninvasive ventilation in acute hypercapnic respiratory failure. Intensive Care Med 2009; 35: 519-526.

9 Girault C, Briel A, Benichou J, et al. Interface strategy during noninvasive positive pressure ventilation for hypercapnic acute respiratory failure. Crit Care Med 2009; 37: 124-131. 
10 Tonnelier JM, Prat G, Nowak E, et al. Noninvasive continuous positive airway pressure ventilation using a new helmet interface: a case-control prospective pilot study. Intensive Care Med 2003; 29: 2077-2080.

11 Principi T, Pantanetti S, Catani F, et al. Noninvasive continuous positive airway pressure delivered by helmet in hematological malignancy patients with hypoxemic acute respiratory failure. Intensive Care Med 2004; 30: $147-150$

12 Antonelli M, Conti G, Pelosi P, et al. New treatment of acute hypoxemic respiratory failure: noninvasive pressure support ventilation delivered by helmet-a pilot controlled trial. Crit Care Med 2002; 30: 602-608.

13 Rocco M, Dell'Utri D, Morelli A, et al. Noninvasive ventilation by helmet or face mask in immunocompromised patients: a case-control study. Chest 2004; 126: 1508-1515.

14 Cosentini R, Brambilla AM, Aliberti S, et al. Helmet continuous positive airway pressure vs oxygen therapy to improve oxygenation in community-acquired pneumonia: a randomized, controlled trial. Chest 2010; 138: $114-120$.

15 Antonelli M, Pennisi MA, Pelosi P, et al. Noninvasive positive pressure ventilation using helmet in patients with acute exacerbation of chronic obstructive pulmonary disease: a feasibility study. Anesthesiology 2004; 100: 16-24.

16 Navalesi P, Costa R, Ceriana P, et al. Noninvasive ventilation in chronic obstructive pulmonary disease patients: helmet versus facial mask. Intensive Care Med 2007; 33: 74-81.

17 Fodil R, Lellouche F, Mancebo J, et al. Comparison of patient-ventilator interfaces based on their computerized effective dead space. Intensive Care Med 2011; 37: 257-262.

18 Olivieri C, Costa R, Spinazzola G, et al. Bench comparative evaluation of a new generation and standard helmet for delivering non-invasive ventilation. Intensive Care Med 2013; 39: 734-738.

19 Vargas F, Thille A, Lyazidi A, et al. Helmet with specific setting versus facemask for noninvasive ventilation. Crit Care Med 2009; 37: 1921-1928.

20 Kendrik KR, Baxi SC, Smith RM. Usefulness of the modified 0-10 Borg scale in assessing the degree of dyspnea in patients with COPD and asthma. J Emerg Nurs 2000; 26: 216-222.

21 Nava S, Ferrer M, Esquinas A, et al. Palliative use of noninvasive ventilation in end-of-life patients with solid tumours: a randomised feasibility trial. Lancet Oncol 2013; 14: 219-227.

22 Kelly BJ, Matthay MA. Prevalence and severity of neurologic dysfunction in critically ill patients. Influence of need for continued mechanical ventilation. Chest 1993; 104: 1818-1824.

23 Charlson ME, Pompei P, Ales KL, et al. A new method of classifying prognostic comorbidity in longitudinal studies: development and validation. J Chronic Dis 1987; 40: 373-383.

24 Vaschetto R, De Jong A, Conseil M, et al. Comparative evaluation of three interfaces for non-invasive ventilation: a randomized cross-over design physiologic study on healthy volunteers. Crit Care 2014; 18: R2.

25 Kramer N, Meyer TJ, Meharg J, et al. Randomized prospective trial of noninvasive positive pressure ventilation in acute respiratory failure. Am J Respir Crit Care Med 1995; 151: 1799-1806.

26 Confalonieri M, Garuti G, Cattaruzza MS, et al. A chart of failure risk for noninvasive ventilation in patients with COPD exacerbation. Eur Respir J 2005; 25: 348-355.

27 Brochard L, Mancebo J, Wysocki M, et al. Noninvasive ventilation for acute exacerbations of chronic obstructive pulmonary disease. N Engl J Med 1995; 333: 817-822.

28 R Development Core Team. A language and environment for statistical computing. www.R-project.com Date last accessed: June 1, 2014. Date last updated: October 7, 2014

29 Pacilli AM, Valentini I, Carbonara P, et al. Determinants of noninvasive ventilation outcomes during an episode of acute hypercapnic respiratory failure in chronic obstructive pulmonary disease: the effects of comorbidities and causes of respiratory failure. Biomed Res Int 2014; 2014: 976783.

30 Pisani L, Carlucci A, Nava S. Interfaces for noninvasive mechanical ventilation: technical aspects and efficiency. Minerva Anestesiol 2012; 78: 1154-1161.

31 Taccone $\mathrm{P}$, Hess D, Caironi $\mathrm{P}$, et al. Continous positive airway pressure delivered with a helmet: effects on carbon dioxide rebreathing. Crit Care Med 2004; 32: 2090-2096.

32 Mojoli F, Iotti GA, Gerletti M, et al. Carbon dioxide rebreathing during noninvasive ventilation delivered by helmet: a bench study. Intensive Care Med 2008; 34: 1454-1460.

33 Carlucci A, Delmastro M, Rubini F, et al. Changes in the practice of noninvasive ventilation in treating COPD patients over 8-years. Intensive Care Med 2003; 29: 419-425.

34 Scandroglio M, Piccolo U, Mazzone E, et al. Use and nursing of the helmet in delivering noninvasive ventilation. Minerva Anestesiol 2002; 68: 475-480. 